\title{
Effects of EDC-PEI heparinization on allogeneic vascular antigens and inflammation levels via a rat abdominal aorta transplantation model
}

\author{
FENG HAN ${ }^{1,2^{*}}$, PUXUN TIAN ${ }^{1,2^{*}}$, XINXIN XIA ${ }^{3}$, YUXIANG WANG $^{1,2}$, MENG DOU $^{1,2}$, \\ JIN ZHENG ${ }^{1,2}$, XIAOMING DING ${ }^{1,2}$, WUJUN XUE ${ }^{1,2}$ and CHENGUANG DING ${ }^{1,2}$ \\ ${ }^{1}$ Department of Kidney Transplantation, Nephropathy Hospital, The First Affiliated Hospital of Xi'an Jiaotong University; \\ ${ }^{2}$ Institute of Organ Transplantation, Xi'an Jiaotong University; ${ }^{3}$ Department of Traditional Chinese Medicine, \\ The First Affiliated Hospital of Xi'an Jiaotong University, Xi'an, Shaanxi 710061, P.R. China
}

Received November 10, 2017; Accepted September 26, 2018

DOI: 10.3892/etm.2018.6879

\begin{abstract}
The objective of this study was to investigate the possibility of increasing the remote patency rate of allogeneic vessel transplantation through studying the effects of N-ethyl-N(3-dimethylaminopropyl)-carbodiimide and polyethyleneimine (EDC-PEI) heparinization on allogeneic vascular antigens and inflammation levels. Forty rats were randomly divided into the control group, the EDC group, the PEI group and the EDC-PEI group. The rat abdominal aorta was used as the object of study, and the transplanted blood vessels were pretreated with EDC as the water-soluble cross-linking agent and PEI as the heparincoated carrier. A rat abdominal aorta allogeneic transplantation model was established. Ultrasonic examination was used for observation of patency of proximal and distal anastomosis in each group. The tissue repair after abdominal aorta transplantation in each group was examined by H\&E staining. The biomechanics, denaturation temperature and blasting strength of each group were compared. The levels of IL-1, IL- 6 and TNF- $\alpha$ in serum of rats were measured by ELISA method, and the expression of MHC-II and $\alpha$-GAL antigens in blood vessels were detected by immunohistochemistry. There were different degrees of thickening and inflammatory cell aggregation in the abdominal aorta of rats in the control, EDC and PEI groups, but there was no obvious lesion in the EDC-PEI group. Compared with the four groups, the mechanical characteristics of the EDC group decreased significantly, and
\end{abstract}

Correspondence to: Dr Chenguang Ding or Dr Puxun Tian, Department of Kidney Transplantation, Nephropathy Hospital, The First Affiliated Hospital of Xi'an Jiaotong University, 277 West Yanta Street, Xi'an, Shaanxi 710061, P.R. China

E-mail: ding_doctor@163.com

E-mail:poma063@126.com

*Contributed equally

Key words: arterial transplantation, inflammation, vascular antigens, prognosis and outcome, atherosclerotic disease the stenosis rate of anastomotic stoma in the EDC group was higher than that in the EDC-PEI and PEI groups $(\mathrm{P}<0.05)$. The denaturation temperature of the PEI group was lower than that of the EDC and EDC-PEI groups $(\mathrm{P}<0.05)$. The mechanical property and vascular bursting strength in the EDC-PEI group were similar to those in the control group. At the same time, it has more significant advantages than the other three groups in removing the vascular antigens MHC-II and $\alpha-G A L$ and reducing the level of inflammatory reaction, thus increasing the remote patency rate of allogeneic vascular transplantation. The inflammatory response and vascular antigenicity after transplantation are effectively reduced via the rat abdominal aorta transplantation model treated with allogeneic EDC-PEI heparinization, which has a higher remote patency rate.

\section{Introduction}

Vascular bypass grafting is a major means of clinical treatment of atherosclerotic vascular disease in vascular surgery, but the remote patency rate of patients after vascular transplantation is relatively low (1-3). The main factor affecting the remote patency rate is the vascular restenosis after transplantation, and it is mainly manifested as intimal hyperplasia and vascular remodeling, both of which are closely related to vascular inflammatory response and immunological rejection $(4,5)$. In this study, the transplanted blood vessels were pretreated with $\mathrm{N}$-ethyl-N-(3-dimethylaminopropyl)-carbodiimide (EDC) as the water-soluble cross-linking agent and polyethyleneimine (PEI) as the heparin-coated carrier (6), so as to investigate the effects of EDC-PEI heparinization on allogeneic vascular antigens and inflammation levels, and discuss the possibility of increasing the remote patency rate of allogeneic vascular transplantation.

\section{Materials and methods}

Objects of study. A total of 40 inbred-line male Wister rats aged 3-4 months weighing 250-350 g were purchased from the Laboratory Animal Center of the First Affiliated Hospital of Xi'an Jiaotong University (Xi'an, China). All animals were 
provided with health certificate from the supplier before purchase and they were housed in cages under specific pathogen-free (SPF) conditions at a constant room temperature of $22-24^{\circ} \mathrm{C}$ with a 12 -h light/dark cycle (lights on: 8 a.m., off: 8 p.m.) and provided ad libitum access to food and water. Rats used in this study were housed in a facility with animal care and use programs accredited by the Association for Assessment and Accreditation of Laboratory Animal Care. The study was approved by the Ethics Committee of the First Affiliated Hospital of Xi'an Jiaotong University.

Animal grouping. The rats were randomly divided into the control group $(n=10)$, the EDC group $(n=10)$, the PEI group $(n=10)$ and the EDC-PEI group $(n=10)$. The control group only received the routine transplantation without special treatment of blood vessels. The EDC group was treated with EDC crosslinking treatment after decellularization in abdominal aorta. The PEI group was directly treated with PEI-loaded heparin without cross-linking treatment. The EDC-PEI group was treated with EDC cross-linking treatment first, and then PEI-loaded heparin.

Establishment of rat abdominal aorta allogeneic transplantation model

Donor operation. The rats were weighed, anaesthetized via intraperitoneal injection of pentobarbital sodium $(50 \mathrm{mg} / \mathrm{kg})$ and fixed. A median incision was made on the abdomen to expose the inferior vena cava and abdominal aorta, and $5 \mathrm{mg} / \mathrm{kg}$ heparin saline was injected intraperitoneally. The abdominal aorta renal artery opening was dissociated till the iliac vascular bifurcation, the proximal and distal ends were clamped using the spring hemostatic clips, and the abdominal aorta from the renal arterial branch to the iliac arterial branch was cut and taken. The dissociated abdominal aorta was quickly rinsed and trimmed in the ice salt water.

EDC-PEI heparinization treatment of transplanted blood vessels in the experimental group

Decellularization in abdominal aorta. Abdominal aorta was soaked in phosphate-buffered saline (PBS) at $-80^{\circ} \mathrm{C}$ for $4 \mathrm{~h}$, bathed in water at $37^{\circ} \mathrm{C}$ for $30 \mathrm{~min}$, and repeatedly frozen and thawed 3 times. Then, it was rinsed with PBS for $24 \mathrm{~h}$, and the solution was replaced once every $6 \mathrm{~h}$, and vibrated at $4^{\circ} \mathrm{C}$. It was vibrated in $0.25 \%$ Triton $\mathrm{X}-100$ and $0.25 \%$ DOC PBS at $37^{\circ} \mathrm{C}$ for $48 \mathrm{~h}$. Then, it was rinsed with PBS again for $24 \mathrm{~h}$ in the same steps as before.

Cross-linking treatment of abdominal aorta after decellularization. The abdominal aorta after decellularization was immersed in 0.05 M MES buffer ( $\mathrm{pH}$ 5.4) for more than $30 \mathrm{~min}$, removed and placed in $215 \mathrm{ml} 0.05 \mathrm{M}$ methyl ester sulfonate (MES) solution containing $1.73 \mathrm{lg}$ EDC and $0.43 \mathrm{lg}$ NHS. The solution was vibrated slightly at room temperature for reaction for $4 \mathrm{~h}$. The substrate was washed with $0.1 \mathrm{M} \mathrm{Na}_{2} \mathrm{HPO}_{4}$ for $2 \mathrm{~h}$ $\left(\mathrm{Na}_{2} \mathrm{HPO}_{4}\right.$ solution was replaced once every $\left.0.5 \mathrm{~h}\right)$ and with distilled water for $2 \mathrm{~h}$ (distilled water was replaced once every $0.5 \mathrm{~h}$ ); after freeze drying, it was stored at $20^{\circ} \mathrm{C}$.

EDC-PEI-loaded heparin. The abdominal aorta after crosslinking treatment was immersed in $10 \mathrm{ml} 0.15 \mathrm{M} \mathrm{NaCl}$ aqueous solution containing $1 \mathrm{mg} / \mathrm{ml} \mathrm{PEI}$ for $30 \mathrm{~min}$, washed with PBS 3 times, placed in $10 \mathrm{ml}$ PBS solution containing $0.5 \mathrm{mg} / \mathrm{ml}$ heparin for $30 \mathrm{~min}$, and washed twice with PBS. The procedure was repeated 15 times to overlay heparin on the specimen layer upon layer.

Biomechanical property detection. The blood vessel in each group was cut along the direction into $0.2 \times 0.4 \mathrm{~cm}$ pieces. The uniaxial breaking test was performed for each group using the EnduraTEC ELF3200 biomechanical material dynamic testing system. The vascular thickness was measured using a micrometer caliper. The blood vessels were pulled at a speed of $10 \mathrm{~mm} / \mathrm{min}$ till vascular tear, and the vascular tension and deformation value were recorded.

Denaturation temperature measurement. The blood vessel in each group was cut into pieces and the denaturation temperature in each group was measured using the differential scanning calorimetry. The heating rate was set at $2^{\circ} \mathrm{C} / \mathrm{min}$.

Vascular bursting strength measurement. The wet abdominal aorta specimens were perfused with normal saline and connected to a pressure pump, and the arterial pressure (set as bursting pressure) after leakage from the vascular wall rupture was recorded.

Recipient operation. Wister rats were weighed and anesthetized, and the abdomen was opened. After resection of the abdominal aorta between two hemostatic clips, approximately $3 \mathrm{~mm}$-long abdominal aorta stump needed to be retained outside the hemostatic clip on each side. The arterial cavities of upper and lower stumps were washed with heparin saline, and the ophthalmic scissors were used to repair the vascular adventitia to $0.5 \mathrm{~mm}$ from the edge of arterial opening. The abdominal aortic vessels of donor were trimmed using the same method, and the donor vessels were placed within the operative region, followed by anastomosis, during which the lumen was washed with heparin water. The anastomotic exudation was detected after operation, the lower hemostatic clip was released, and the leakage was checked. Then the upper hemostatic clip was also released. The vascular filling, instant patency rate and iliac artery pulse were detected. The abdomen was sutured layer by layer after no active bleeding.

Observation indexes. Blood specimens of recipient rats were retained before operation and at sacrifice, and centrifuged at $670.8 \mathrm{x} \mathrm{g}$ at room temperature for $10 \mathrm{~min}$. The serum was numbered and stored separately at $-20^{\circ} \mathrm{C}$ for standby application. Before execution, transplanted vascular patency was detected via HP Sonos 4500 ultrasound. The recipient rats were executed, $1 \mathrm{~cm}$-long abdominal aorta transplanted vessels were taken, and $5 \mu \mathrm{m}$-thick sections were frozen.

Detection of interleukin-1 (IL-1), IL-6 and tumor necrosis factor- $\alpha(T N F-\alpha)$. IL-1, IL-6 and TNF- $\alpha$ were detected via enzyme-linked immunosorbent assay (ELISA) according to the instructions of kits.

Detection of vascular antigens. Major histocompatibility complex (MHC)-II antigen detection: The frozen sections of transplanted abdominal aorta were fixed with acetone for 


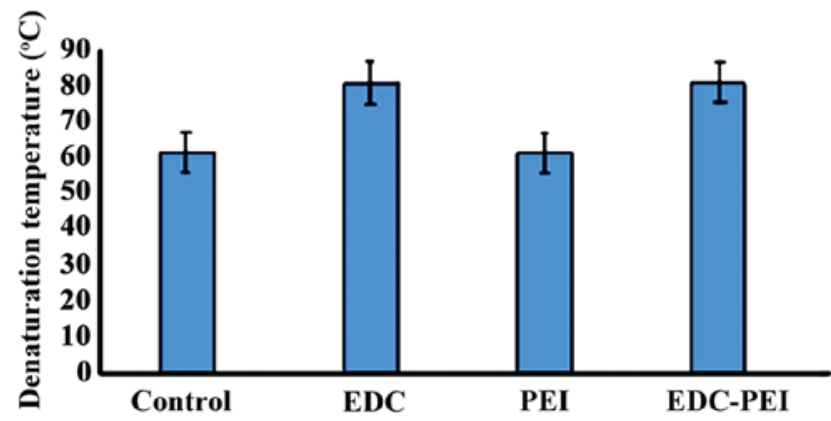

Figure 1. Comparison of pathological characteristics in each group. Control group: vascular media thickening, inflammatory cell infiltration. EDC group: thickening of vascular mesenchymal cells. PEI group: partially elastic fiber glass-like denaturation. EDC-PEI group: no significant lesion of vascular endothelial cells.

Table I. Comparisons of distal anastomosis peak flow and stenosis rate in each group.

\begin{tabular}{lcc}
\hline Groups $(\mathrm{n}=24)$ & $\begin{array}{c}\text { Peak flow } \\
(\mathrm{cm} / \mathrm{sec})\end{array}$ & $\begin{array}{c}\text { Stenosis } \\
\text { rate }(\%)\end{array}$ \\
\hline Control & $169.8 \pm 21.6$ & 33.3 \\
EDC & $148.2 \pm 23.2$ & $8.3^{\mathrm{a}}$ \\
PEI & $128.3 \pm 20.2^{\mathrm{a}}$ & $0^{\mathrm{b}}$ \\
EDC-PEI & $127.2 \pm 18.8^{\mathrm{a}}$ & $0^{\mathrm{b}}$ \\
\hline
\end{tabular}

${ }^{\mathrm{a}} \mathrm{P}<0.05 ;{ }^{\mathrm{b}} \mathrm{P}<0.01$.

10 min, and soaked in 3\% hydrogen peroxide methanol solution for $10 \mathrm{~min}$ according to the instructions of the kit, followed by semi-quantitative analysis of MHC-II antigen level.

$\alpha-G A L$ antigen detection: i) Immunohistochemical method: The glass slide was treated with hexyltriethoxysilane, baked in an oven at $58-60^{\circ} \mathrm{C}$ for $60 \mathrm{~min}$, and stored at $4^{\circ} \mathrm{C}$ for standby application. After antigen retrieval via microwave, the Bandeiraea simplicifolia isolectin-B4 (BSI-B4) was added dropwise to soak and incubate the antigen at $37^{\circ} \mathrm{C}$ for $20 \mathrm{~min}$; then the antigen was washed with $0.01 \mathrm{M}$ PBS and added with streptavidin-biotin complex (SABC) for incubation at $37^{\circ} \mathrm{C}$ for $20 \mathrm{~min}$, and washed again with PBS, followed by color development via diaminobenzidine (DAB), washing with distilled water, dehydration, transparency, sealing and microscopic examination. Brown yellow particles under microscope indicated positive (+), while no staining indicated negative (-). ii) ELISA: First the reagents, standard materials and samples required were prepared. The sample was diluted, and then the standard solution was prepared. Diluent (100 $\mu \mathrm{l})$ was added into each well, then added with $50 \mu \mathrm{l}$ standard solution and sample and covered with the tape provided in the package, followed by incubation at room temperature for $2 \mathrm{~h}$. Then each well was sucked and rinsed 4 times, the cleaning fluid was sucked dry, and the plate was placed upside down on a clean paper towel. $\alpha$-GAL conjugate $(200 \mu \mathrm{l})$ was added into each well covered with the tape, followed by incubation at room temperature for $2 \mathrm{~h}$. The above sucking and rinsing steps were repeated again. Then $200 \mu \mathrm{l}$ substrate solution was added into

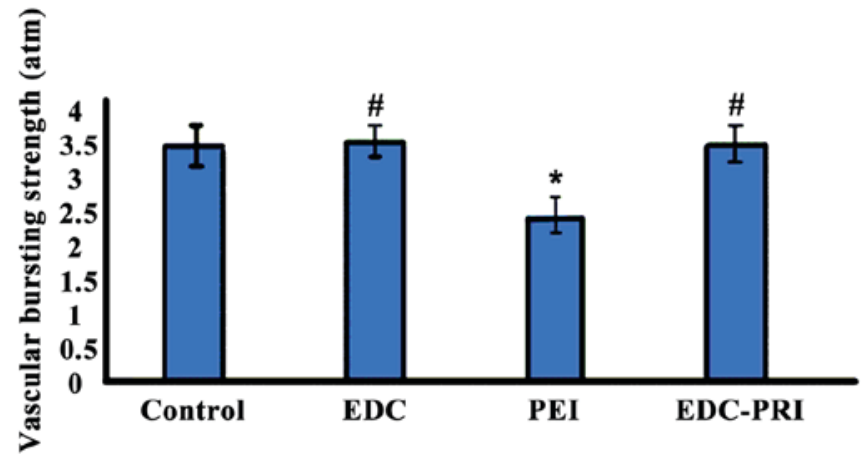

Figure 2. Comparison of vascular bursting strength in each group. ${ }^{*} \mathrm{P}<0.01$ compared with the control group. ${ }^{~} \mathrm{P}>0.05$ compared with the control group. EDC, N-ethyl-N-(3-dimethylaminopropyl)-carbodiimide; PEI, polyethyleneimine.

each well for incubation in a dark place at room temperature for $30 \mathrm{~min}$, and $50 \mu \mathrm{l}$ stop buffer was added. Finally, the optical density (OD) value was measured and recorded.

Statistical analysis. Statistical Product and Service Solutions (SPSS) 20.0 software package (IBM Corp., Armonk, NY, USA) was used for the statistical analysis of all data. Data were presented as mean \pm standard deviation. The inspection level $\alpha=0.05$. ANOVA was used for comparison between multiple groups and the post hoc test was Tukey's test. $\mathrm{P}<0.05$ indicated that the difference was statistically significant.

\section{Results}

Comparison of pathological characteristics in each group. In the control group, the thickness of the aorta was thickened, the lumen was narrow, and a large number of inflammatory cells were accumulated in the middle membrane. There was partial thickening of vascular mesenchymal cells in the EDC group. In the PEI group, there were partial elastic fiber glass degeneration and some foam cells in abdominal aorta endothelial cells. In the EDC-PEI group, the structure of vascular smooth muscle cells, elastic fibers and collagen fibers were normal. EDC-PEI treatment can significantly protect the abdominal aorta tissue morphology, indicating that EDC-PEI treatment can significantly protect the abdominal aorta tissue morphology (Fig. 1).

Comparison of vascular ultrasound results in each group. The ultrasound examinations in the PEI and EDC-PEI groups showed that the proximal and distal vascular anastomoses were smooth without changes in blood flow rate. The peak flow rates of distal abdominal aorta anastomoses in the EDC and control groups were significantly higher than those in the PEI and EDC-PEI groups. The stenosis rates (stenosis $>50 \%$ ) of distal vascular anastomoses in the EDC and control groups were $8.3 \%$ and $33.3 \%$, respectively (Table I).

Comparison of mechanical property in each group. Compared with those in the control group, the maximum load and maximum tensile strength in the EDC, PEI and EDC-PEI groups were all decreased, and the differences were statistically significant. The elastic modulus in the EDC, PEI and EDC-PEI 
Table II. Comparison of mechanical property in each group.

\begin{tabular}{lcccr}
\hline Groups $(\mathrm{n}=24)$ & $\begin{array}{c}\text { Elastic modulus } \\
(\mathrm{MPa})\end{array}$ & $\begin{array}{c}\text { Maximum tensile } \\
\text { strength }(\mathrm{MPa})\end{array}$ & $\begin{array}{c}\text { Maximum } \\
\text { load }(\mathrm{N})\end{array}$ & $\begin{array}{c}\text { Stretch } \\
\text { rate }(\%)\end{array}$ \\
\hline Control & $45.23 \pm 2.45$ & $10.26 \pm 1.55$ & $42.51 \pm 2.58$ & $34.56 \pm 2.62$ \\
EDC & $28.67 \pm 3.47^{\mathrm{a}}$ & $6.23 \pm 1.19^{\mathrm{a}}$ & $16.62 \pm 1.42^{\mathrm{a}}$ & $33.63 \pm 3.29$ \\
PEI & $30.09 \pm 1.83^{\mathrm{a}}$ & $5.15 \pm 0.64^{\mathrm{a}}$ & $25.56 \pm 1.77^{\mathrm{a}}$ & $35.35 \pm 2.67$ \\
EDC-PEI & $35.23 \pm 3.05^{\mathrm{a}}$ & $7.16 \pm 0.32^{\mathrm{a}}$ & $27.14 \pm 2.01^{\mathrm{a}}$ & $37.43 \pm 2.72$ \\
\hline
\end{tabular}

${ }^{\mathrm{a}} \mathrm{P}<0.05$.

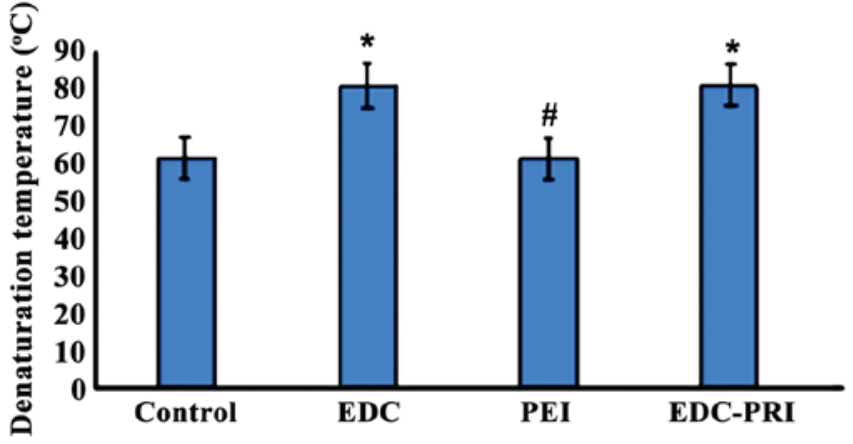

Figure 3. Comparison of denaturation temperature in each group. ${ }^{*} \mathrm{P}<0.05 \mathrm{com}-$ pared with the control group. ${ }^{\#} \mathrm{P}>0.05$ compared with the control group. EDC, N-ethyl-N-(3-dimethylaminopropyl)-carbodiimide; PEI, polyethyleneimine.

groups significantly declined, indicating that the extracellular matrix is damaged seriously after treatment with EDC, PEI and EDC-PEI heparinization. The mechanical property in EDC-PEI group was the optimal among three groups (Table II).

Comparison of vascular bursting strength in each group. The bursting pressure was $3.33 \pm 0.30$ atm in the control, $3.41 \pm 0.25 \mathrm{~atm}$ in the EDC, $2.35 \pm 0.22 \mathrm{~atm}$ in the PEI, and $3.36 \pm 0.31 \mathrm{~atm}$ in the EDC-PEI groups, suggesting that the vascular mechanical strength in the PEI group was weakened by decellularization $(\mathrm{P}<0.01)$, while the vascular mechanical properties in the EDC and EDC-PEI groups after EDC crosslinking treatment had no statistically significant differences compared with that in the control group (Fig. 2).

Comparison of denaturation temperature in each group. The denaturation temperature was $61.2 \pm 0.4^{\circ} \mathrm{C}$ in the control, $80.7 \pm 0.5^{\circ} \mathrm{C}$ in the EDC, $61.1 \pm 0.5^{\circ} \mathrm{C}$ in the PEI and $80.6 \pm 0.6^{\circ} \mathrm{C}$ in the EDC-PEI groups, respectively. The denaturation temperature in the EDC and EDC-PEI groups had statistically significant differences compared with that in the control group $(\mathrm{P}<0.05)$, indicating that EDC cross-linking treatment can improve the thermal stability of collagen (Fig. 3).

Levels of serum inflammatory factors (IL-1, IL-6 and TNF- $\alpha$ ) in each group. The changes in serum inflammatory factor levels in rat abdominal aorta allogeneic transplantation model are shown in Table III. The serum inflammatory factor levels in the control group receiving conventional treatment were significantly increased after transplantation, but the increases
Table III. IL-1, IL-6 and TNF- $\alpha$ in each group.

\begin{tabular}{llll}
\hline Groups $(\mathrm{n}=24)$ & $\mathrm{IL}-1(\mathrm{pg} / \mathrm{ml})$ & $\mathrm{IL}-6(\mathrm{pg} / \mathrm{ml})$ & $\mathrm{TNF}-\alpha(\mathrm{pg} / \mathrm{ml})$ \\
\hline Control & $152.51 \pm 20.05$ & $68.36 \pm 15.55$ & $48.46 \pm 12.45$ \\
EDC & $118.28 \pm 16.85^{\mathrm{a}}$ & $47.63 \pm 12.79^{\mathrm{a}}$ & $34.14 \pm 14.35^{\mathrm{a}}$ \\
PEI & $132.63 \pm 22.65^{\mathrm{a}, \mathrm{b}}$ & $76.65 \pm 17.74^{\mathrm{a}, \mathrm{b}}$ & $54.67 \pm 14.50^{\mathrm{a}, \mathrm{b}}$ \\
EDC-PEI & $72.52 \pm 15.21^{\mathrm{a}, \mathrm{b}}$ & $36.12 \pm 14.05^{\mathrm{a}, \mathrm{b}}$ & $28.26 \pm 10.42^{\mathrm{a}, \mathrm{b}}$ \\
\hline
\end{tabular}

${ }^{a} \mathrm{P}<0.05$ vs. the control group. ${ }^{\mathrm{b}} \mathrm{P}>0.05$, vs. the EDC group.

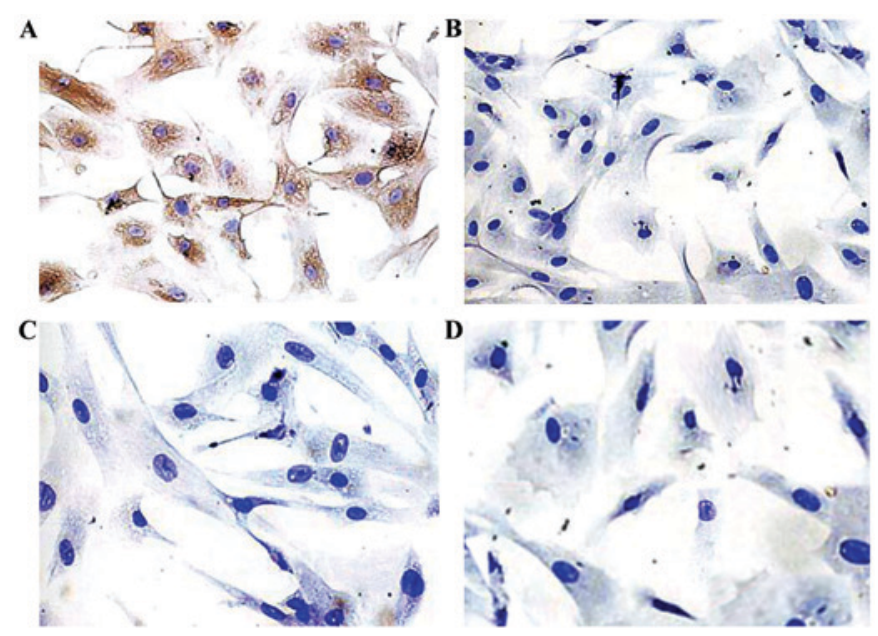

Figure 4. MHC-II antigen level (immunohistochemistry). (A) Control group (vascular endothelial cell MHC-II is stained brown). (B) EDC group (vascular endothelial cell MHC-II is stained negatively). (C) PEI group (vascular endothelial cell MHC-II is stained negatively). (D) EDC-PEI group (vascular endothelial cell MHC-II is stained negatively).

in inflammation levels in the EDC, PEI and EDC-PEI groups were less than that in the control group, and the differences were statistically significant.

Comparisons of vascular antigen (MHC-II and $\alpha-G A L)$ levels in each group. Immunohistochemical results showed that the vascular endothelial cells in the control group were stained brown, and a large number of brown yellow particle sediments could be seen, but smooth muscle cells, elastic fibers and collagen fibers were not stained. After treatment with EDC, PEI or EDC-PEI, vascular endothelial cells, smooth muscle cells, elastic fibers and collagen fibers were not stained (Fig. 4). 
Table IV. Comparison of MHC-II and $\alpha$-GAL antigen levels in each group (ELISA).

\begin{tabular}{lcc}
\hline Groups $(\mathrm{n}=24)$ & MHC-II & $\alpha-\mathrm{GAL}(\mathrm{U} / \mathrm{mg})$ \\
\hline Control & $0.2875 \pm 0.0245$ & $1.26 \pm 0.55$ \\
EDC & $0.2163 \pm 0.0123^{\mathrm{a}}$ & $0.23 \pm 0.19^{\mathrm{b}}$ \\
PEI & $0.2354 \pm 0.0212^{\mathrm{a}}$ & $0.15 \pm 0.14^{\mathrm{b}}$ \\
EDC-PEI & $0.2272 \pm 0.0078^{\mathrm{a}}$ & $0.16 \pm 0.15^{\mathrm{b}}$ \\
\hline
\end{tabular}

${ }^{\mathrm{a}} \mathrm{P}<0.05 ;{ }^{\text {b }} \mathrm{P}<0.01$.

ELISA revealed that the levels of MHC-II and $\alpha$-GAL in the EDC, PEI and EDC-PEI groups were significantly lower than those in the control group $(\mathrm{P}<0.05$ or $\mathrm{P}<0.01)$ (Table IV).

\section{Discussion}

Vascular disease is one of the human diseases with the highest incidence rate, in which the atherosclerotic lesions, functional changes and inflammatory lesions, can occur in blood vessels (7-10). The treatment methods of vascular disease include bypass grafting, percutaneous transluminal angioplasty or stent implantation, gene therapy and drug therapy (11). Vascular bypass grafting is an important means of treatment of vascular disease, and the vascular graft materials in clinical application include the autologous blood vessels, allogeneic blood vessels and artificial materials (12). Treatment with autologous vascular tissue is ideal, but it is at the expense of health, and its source is very limited. Moreover, due to the immunological rejection of allogeneic or xenogeneic blood vessels, its application is limited, and the immune reaction and inflammatory responses often lead to the arteriosclerosis and thrombosis of transplanted vessels, affecting the treatment effect. The ideal allogeneic vascular transplantation has three conditions (13). First, no antigenicity; secondly, maintain the vascular structure and vascular physical property; thirdly, better histocompatibility. At present, in order to reduce the immunogenicity of allogeneic or xenogeneic blood vessels, the cell components are first removed and then crosslinked with the structural proteins; the cells, cell debris and lipid in allogeneic or xenogeneic vessels are removed using a variety of methods, that is, removing the substances that cause tissue antigenicity, and preserving the extracellular matrix-based components, and maintaining the original mechanical property and forming of blood vessels (14).

Previous studies have shown that the long-term high vascular patency rate after bypass grafting is closely related to the physical property of blood vessels. If the allogeneic blood vessels have poor physical properties, it will directly affect the host's hemodynamics and the pressure wave propagation rate, cause wave reflection and form the eddy at the junction, leading to blood coagulation, thrombosis and vascular endothelial cell proliferation (15). Due to the different expansion rates of vascular diameter, the anastomotic stress is increased, resulting in shear stress and fibrous tissue hyperplasia (4). In this study, allogeneic rat abdominal aorta was selected for vessel study, and the vascular surface was modified to improve its blood compatibility, reduce thrombosis and prevent vascular occlusion.
Inflammatory response will occur after vascular transplantation. Multiple inflammatory factors are involved in the occurrence of inflammatory response after vascular transplantation, which affect the function and number of endothelial progenitor cells through different signaling pathways, thus affecting the vascular repair; and the B lymphocytes, $\mathrm{T}$ lymphocytes and mononuclear-macrophages are activated, resulting in a large amount of IL and TNF- $\alpha(16,17)$. In the early stage of inflammatory response, inflammatory cells and inflammatory factors can stimulate the mobilization and homing of endothelial progenitor cells, which is conducive to damage repair (18). However, the long-term inflammatory stimuli and high-level inflammatory factors can reduce the number of endothelial progenitor cells in circulation, accelerate the apoptosis of endothelial progenitor cells, and inhibit the adhesion and proliferation of endothelial progenitor cells, thus harming the damage repair and leading to the occurrence and development of vascular injury after transplantation (19-21). In this study, the aorta was thickened, the lumen was narrow, and a large number of inflammatory cells were accumulated in the middle membrane in the control group. There was partial thickening of vascular mesenchymal cells in the EDC group. In the PEI group, there were partial elastic fiber glass degeneration and some foam cells in abdominal aorta endothelial cells. In the EDC-PEI group, the structure of vascular smooth muscle cells, elastic fibers and collagen fibers were normal. EDC-PEI treatment can significantly protect the abdominal aorta tissue morphology. Further detection of serum inflammatory factors found that IL-1, IL- 6 and TNF- $\alpha$ in the control group were constantly increased, leading to vascular anastomotic stenosis later. However, in the EDC-PEI group, inflammatory factors were secreted early after operation, but returned to normal levels rapidly without causing further damage to vascular endothelium, so vascular anastomotic stenosis did not occur. These results indicated that EDC-PEI treatment can significantly protect the abdominal aorta tissue morphology.

MHC antigens of endothelial cells belong to the important immunogens and target antigens of allogeneic vascular transplantation immunity (22). To reduce the antigenicity of allogeneic blood vessels, the researchers have tried various methods, including formaldehyde, glycerol and ethanol soaking, or polyepoxy compound, glutaraldehyde cross-linking treatment of allogeneic blood vessels. However, the remote patency rate after transplantation is relatively low (23-25). Studies have found that EDC cross-linking treatment and surface modification, heparin loading can block part of the MHC antigenic determinants, so as to better preserve the vascular structure; besides, the spatial conformation of protein can be changed to reduce the expression level of MHC antigen, thus effectively reducing the vascular antigenicity and ultimately preventing thrombosis. The results of this study revealed that the expression of MHC antigen in the experimental group was significantly lower than that in the control group, so it had superior histocompatibility and remote patency rate of blood vessels.

In conclusion, the inflammatory response and vascular antigenicity after transplantation are effectively reduced via the rat abdominal aorta transplantation model treated with allogeneic EDC-PEI heparinization, which has a higher remote patency rate. 


\section{Acknowledgements}

We thank Ms. Xiaoli He and Peidan Kuang for their excellent laboratory management.

\section{Funding}

The study was supported by Scientific and technological project of Shaanxi Province (no. 2016SF-246). The National Nature Science Foundation of China (no. 81670681).

\section{Availability of data and materials}

The datasets used during the present study are available from the corresponding author upon reasonable request.

\section{Authors' contributions}

FH and CD conceived and designed the study. FH, PT, XX, YW, MD JZ, XD, WX performed the experiments. FH, PT wrote the paper. FH, PT and CD reviewed and edited the manuscript. All authors read and approved the manuscript and agree to be accountable for all aspects of the research in ensuring that the accuracy or integrity of any part of the work are appropriately investigated and resolved.

\section{Ethics approval and consent to participate}

The study was approved by the Ethics Committee of the First Affiliated Hospital of Xi'an Jiaotong University (Xi'an, China).

\section{Patient consent for publication}

Not applicable.

\section{Competing interests}

The authors declare that they have no competing interests.

\section{References}

1. Ohmes LB, Di Franco A, Di Giammarco G, Rosati CM, Lau C, Girardi LN, Massetti M and Gaudino M: Techniques for intraoperative graft assessment in coronary artery bypass surgery. J Thorac Dis 9 (Suppl 4): S327-S332, 2017.

2. Raja SG: Two decades of off-pump coronary artery bypass surgery: Harefield experience. J Thorac Dis 8 (Suppl 10): S824-S828, 2016.

3. He GW and Taggart DP: Antispastic management in arterial grafts in coronary artery bypass grafting surgery. Ann Thorac Surg 102: 659-668, 2016.

4. Ward AO, Caputo M, Angelini GD, George SJ and Zakkar M: Activation and inflammation of the venous endothelium in vein graft disease. Atherosclerosis 265: 266-274, 2017.

5. Meng F, Ma J, Wang W and Lin B: Meta-analysis of interleukin 6,8 , and 10 between off-pump and on-pump coronary artery bypass groups. Bosn J Basic Med Sci 17: 85-94, 2017.

6. Lee W, Park KD, Han KD, Suh H, Park JC and Kim YH Heparinized bovine pericardium as a novel cardiovascular bioprosthesis. Biomaterials 21: 2323-2330, 2000.

7. Nosalski R and Guzik TJ: Perivascular adipose tissue inflammation in vascular disease. Br J Pharmacol 174: 3496-3513, 2017

8. Lénárt N, Brough D and Dénes Á: Inflammasomes link vascular disease with neuroinflammation and brain disorders. J Cereb Blood Flow Metab 36: 1668-1685, 2016.

9. Amlie-Lefond C and Shaw D: Vascular disease. Handb Clin Neurol 136: 1159-1171, 2016.
10. de Franciscis S, Metzinger L and Serra R: The Discovery of novel genomic, transcriptomic, and proteomic biomarkers in cardiovascular and peripheral vascular disease: The state of the art. BioMed Res Int 2016: 7829174, 2016.

11. LukitschI, KehrJ, ChaykovskaL, WallukatG,Nieminen-Kelhä M, Batuman V, Dragun D and Gollasch M: Renal ischemia and transplantation predispose to vascular constriction mediated by angiotensin II type 1 receptor-activating antibodies. Transplantation 94: 8-13, 2012.

12. Yin $\mathrm{H}$ and Pickering JG: Cellular senescence and vascular disease: Novel routes to better understanding and therapy. Can J Cardiol 32: 612-623, 2016.

13. Moore TM, Gendler E and Gendler E: Viruses adsorbed on musculoskeletal allografts are inactivated by terminal ethylene oxide disinfection. J Orthop Res 22: 1358-1361, 2004.

14. Cheshire PA, Herson MR, Cleland $\mathrm{H}$ and Akbarzadeh S: Artificial dermal templates: A comparative study of NovoSorb ${ }^{\mathrm{TM}}$ Biodegradable Temporising Matrix (BTM) and Integra(®) Dermal Regeneration Template (DRT). Burns 42: 1088-1096, 2016.

15. Han Y, Choo SJ, Kwon H, Lee JW, Chung CH, Kim H, Kwon TW and Cho YP: Effects of upper-extremity vascular access creation on cardiac events in patients undergoing coronary artery bypass grafting. PLoS One 12: e0184168, 2017.

16. Weldon JE, Xiang L, Zhang J, Beers R, Walker DA, Onda M, Hassan R and Pastan I: A recombinant immunotoxin against the tumor-associated antigen mesothelin reengineered for high activity, low off-target toxicity, and reduced antigenicity. Mol Cancer Ther 12: 48-57, 2013.

17. Patris E, Giakoumidakis K, Patris V, Kuduvalli M, Argiriou M, Charitos C, Kalaitzis C and Touloupidis S: Perioperative prostate specific antigen levels among coronary artery bypass grafting patients: Does extracorporeal circulation and body temperature induce prostate specific antigen levels alterations? Urol Ann 7: 58-62, 2015.

18. Opfermann P, Derhaschnig U, Felli A, Wenisch J, Santer D, Zuckermann A, Dworschak M, Jilma B and Steinlechner B: A pilot study on reparixin, a CXCR $1 / 2$ antagonist, to assess safety and efficacy in attenuating ischaemia-reperfusion injury and inflammation after on-pump coronary artery bypass graft surgery. Clin Exp Immunol 180: 131-142, 2015.

19. Müller S, Rihs S, Schneider JM, Paredes BE, Seibold I, Brunner T and Mueller C: Soluble TNF-alpha but not transmembrane TNF-alpha sensitizes $\mathrm{T}$ cells for enhanced activation-induced cell death. Eur J Immunol 39: 3171-3180, 2009.

20. Guo ZP, Hou HT, Jing R, Song ZG, Liu XC and He GW: Plasma protein profiling in patients undergoing coronary artery bypass grafting surgery and clinical significance. Oncotarget 8 : 60528-60538, 2017.

21. Abraham AC, Shah SA and Thomopoulos S: Targeting inflammation in rotator cuff tendon degeneration and repair. Tech Shoulder Elbow Surg 18: 84-90, 2017.

22. Kimura T, Tse K, McArdle S, Gerhardt T, Miller J, Mikulski Z, Sidney J, Sette A, Wolf D and Ley K: Atheroprotective vaccination with MHC-II-restricted ApoB peptides induces peritoneal IL-10-producing CD4 T cells. Am J Physiol Heart Circ Physiol 312: H781-H790, 2017.

23. Schmid PM, Bouazzaoui A, Schmid K, Birner CM, Schach C, Maier LS, Holler E and Endemann DH: Vascular alterations in a murine model of acute graft-versus-host disease are associated with decreased serum levels of adiponectin and an increased activity and vascular expression of indoleamine 2,3-dioxygenase. Cell Transplant 25: 2051-2062, 2016

24. Mazzaccaro D, De Febis E, Settembrini AM, Tassinari L, Carmo $M$ and Settembrini PG: Long-term results of PTFE trilaminate graft versus venous graft and composite graft for below-the-knee revascularization. J Cardiovasc Surg (Torino) 55: 685-691, 2014.

25. Malinska A, Podemska Z, Sujka-Kordowska P, Witkiewicz W, Nowicki M, Perek B and Witt M: Caveolin 2: A facultative marker of unfavourable prognosis in long-term patency rate of internal thoracic artery grafts used in coronary artery bypass grafting. Preliminary report. Interact Cardiovasc Thorac Surg 24: 714-720, 2017. 